\title{
Thalidomide enhanced the efficacy of CHOP chemotherapy in the treatment of diffuse large B cell lymphoma: A phase II study
}

\author{
Dongmei $\mathrm{Ji}^{1}$, Qiu Li ${ }^{2}$, Junning Cao ${ }^{1}$, Ye Guo ${ }^{1}$, Fangfang Lv ${ }^{1}$, Xiaojian Liu ${ }^{1}$, Biyun \\ Wang $^{1}$, Leiping Wang ${ }^{1}$, Zhiguo Luo ${ }^{1}$, Jianhua Chang ${ }^{1}$, Xianghua Wu ${ }^{1}$, Xiaonan \\ Hong $^{1}$ \\ ${ }^{1}$ Department of Medical Oncology, Fudan University Shanghai Cancer Center, Department of Oncology, Shanghai Medical \\ College, Fudan University, Shanghai 200032, P.R. China \\ ${ }^{2}$ Department of Medical Oncology, West China Hospital of Medicine, Sichuan University, Chengdu 610041, P.R. China \\ Correspondence to: Xianghua Wu, e-mail: wuxh2015@163.com \\ Xiaonan Hong, e-mail: xnhong@126.com
}

Keywords: thalidomide, chop, diffuse large B-cell lymphoma

Received: November 09, $2015 \quad$ Accepted: April 02, 2016

Published: April 25, 2016

\section{ABSTRACT}

Cyclophosphamide, doxorubicin, vincristine, and prednisolone plus rituximab ( $\mathrm{R}-\mathrm{CHOP}$ ) is the standard treatment for patients with diffuse large $\mathrm{B}$ cell lymphoma (DLBCL). However, rituximab cannot be popularly applied in a considerable number of patients with DLBCL because of economic reasons. To develop a new regimen to improve the outcome of these patients is extremely important. In our study, sixty five patients with DLBCL were randomly assigned to thalidomide plus CHOP group $(n=32)$ or to CHOP alone group $(n=33)$. Objective response rates (ORR) and complete remission rates (CRR) were $96.7 \%$ and $80.6 \%$ in T-CHOP group versus $78.9 \%$ and $57.8 \%$ in CHOP group, respectively $(P<0.05)$. At a median follow-up of 96 months, median PFS for T-CHOP group was still not reached yet, and in CHOP group it was 22.9 months $(95 \% \mathrm{CI}[0-50.4])$. $(P=0.163)$. Median overall survival $(O S)$ for $\mathrm{T}-\mathrm{CHOP}$ group was also not reached, and the estimated median OS for CHOP group was 83.5 months, the difference of OS between the two groups is not significant $(p=0.263)$. But, in patients with Bcl-2 positive and Bcl-6 negative, the median PFS in T-CHOP group was longer than that in CHOP group (111.0 vs 8.5 months $(P=0.017)$. In addition, thalidomide did not significantly increase the grade 3/4 toxicity of CHOP. We concluded that the addition of thalidomide to the CHOP regimen significantly improved the CRR and showed a trend of improving clinical outcome in patients with DLBCL, especially for patients with $\mathrm{Bcl}-2$ positive and $\mathrm{Bcl}-6$ negative $\mathrm{B}$-cell phenotype, without increased toxicity.

\section{INTRODUCTION}

DLBCL is the most common type of malignant lymphoma, accounting for about $31 \%$ of all NHL [1]. CHOP scheme has been the standard chemotherapy regimen in the treatment of advanced NHL for many years [2-4]. The five year survival rate of the CHOP regimen in the treatment of DLBCL is about $45 \%-46 \%$ [5]. There are still more than half of DLBCL patients eventually died of the disease.

Rituximab, a chimeric monoclonal antibody targeted CD20 antigen, can be used for the treatment of CD20 positive B cell lymphoma. Compared with $\mathrm{CHOP}$ scheme, rituximab plus $\mathrm{CHOP}$ (R-CHOP) can significantly improve complete remission rate, and prolong event free survival (EFS) and OS [6, 7]. And FDA has approved this drug for treating chemo-naïve DLBCL. However, according to the Chinese public medical insurance policy, rituximab is not covered by the public medical insurance. Rituximab cannot be popularly applied in a considerable number of patients with DLBCL in China and other developing country. Therefore, it is important to explore a new economic regimen to improve the outcome of this patient population.

Angiogenesis play an important role in tumor invasion and metastasis. Anti-angiogenesis therapy 
has become an important part of the comprehensive treatment for malignant tumors. It is reported that $60 \%$ of the DLBCL specimens showed higher local vascular endothelial growth factor (VEGF) expression, higher VEGF receptor (VEGFR) expression and correspondingly higher micro-vessel density [8], which provides a theoretical foundation for the use of anti-angiogenesis therapy in patients with DLBCL.

DLBCL is a heterogeneous disease with different morphological and molecular characteristics [9]. It can be further divided into two subtypes, germinal center B cells (GCB) subtype and non-GCB subtype [10]. Patients with the non-GCB subtype have a distinctly inferior prognosis, which can be attributed to the constitutive I kappa B kinase

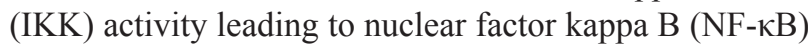
activation, but it is not seen in GCB subtype DLBCL [11].

Thalidomide is a kind of glutamate derivatives. In the late of last century, people found that thalidomide can inhibit angiogenesis by blocking bFGF and VEGF, and it can also modulate the immune system by co-stimulating $\mathrm{T}$ cell proliferation [12-14]. In recent years, some study found that thalidomide can induce the apoptosis of tumor cells and some found it can improve the weight in cancer patients with cachexia $[15,16]$. In addition, thalidomide can also inhibit the IKK activity and block the activation of NF-kappa B [17]. In a phase II study, thalidomide combined with rituximab was applied in refractory or relapsed mantel cell lymphoma patients. This regimen was well tolerated and achieved marked efficacy of $31 \%$ complete remission rate $(\mathrm{CR})$ and $81 \%$ objective response rate (ORR) [18].

In this open-label, randomized, controlled study, the efficacy and tolerability were compared between thalidomide combined with $\mathrm{CHOP}$ (T-CHOP) and CHOP alone in chemo-naïve DLBCL patients. (This clinical trial began in Feb, 2006, and was not registered in ClinicalTrials.gov.)

\section{RESULTS}

\section{Patients' characteristics}

A total of 66 patients were enrolled between February 2006 and June 2007. One patient assigned to the T-CHOP group did not receive any trial medication because he was found to have pulmonary tuberculosis and he was referred to Shanghai Municipal Center for Disease Control and Prevention (CDC) for further treatment; 65 patients were included in the final analysis (CHOP, $n=33$; $\mathrm{T}-\mathrm{CHOP}, \mathrm{n}=32$ ). One patient in T-CHOP group and two patients in CHOP group had cyclophosphamide and epirubicine dose reduction to $75 \%$. In T-CHOP group, one patient stopped to receive thalidomide after the first cycle of treatment because of the onset of angina, and another three patients continued to receive thalidomide at a dose of $200 \mathrm{mg}$ because they had incontinent urinate when the dosage increased to $400 \mathrm{mg}$ per day. There were no significant differences between the two groups in any of the baseline clinical characteristics (Table 1). Central review of pathology was performed on lymph node material from $100 \%$ of the patients. All cases entered in the study were included in this report. IPI scores were balanced across groups, with most patients (52.3\%) having scores of 0 or 1 (Table 1); although not part of the original inclusion criteria, $43.7 \%$ of patients randomized to T-CHOP and $51.5 \%$ of those randomized to CHOP had scores of 2 to 5 according to the International Prognostic Index (IPI) [22].

The baseline characteristics were also balanced between CHOP and T-CHOP group in different Bcl-2 and Bcl-6 status patients (see Supplementary Tables 1-4).

\section{Efficacy}

In this study, $\mathrm{CR}$ rate in T-CHOP group was higher than that in CHOP group, $(80.6 \%$ vs $57.8 \%, \mathrm{P}=0.039)$. Overall response rate (ORR, $\mathrm{CR}+\mathrm{PR}$ ) in CHOP group was $78.8 \%(26 / 33)$ and in T-CHOP group was 96.9\% (31/32) $(\mathrm{P}=0.030$, Fisher's exact test, 1 -sided) (Table 2$)$.

At a median follow-up of 96 months, median PFS for T-CHOP group was not reached yet (estimated mPFS was 69.9 months), and for CHOP group it was 22.9 months (95\% CI [0-50.4]). Median OS for T-CHOP group was not reached, and the estimated median OS for CHOP group was 83.5 months. The survival curves of PFS and OS between these two groups separated, but the differences were not significant, with P values of 0.237 and 0.396 , respectively (Figure 1). Figure 2 showed the PFS and OS curves in different $\mathrm{Bcl}-2$ and $\mathrm{Bcl}-6$ status patients. Patients with tumor tissue Bcl-2 positive and Bcl-6 negative (Bcl2+/Bcl-6-) have the worst outcomes.

The sample size of Bcl-2+/Bcl-6- patients was 11, and Life Tables method was applied to compare the PFS and OS between T-CHOP and CHOP group. The mPFS for this group of patients treated with T-CHOP was 111.0 months, and for those treated with CHOP was 8.5 months. T-CHOP showed significant superiority over CHOP in PFS in Bcl-2+/Bcl-6- patients $(\mathrm{P}=0.017$ ) (Figure 3A). In this group of patients, the mOS for T-CHOP group was 111.0 months, and for CHOP group was 31.5 months. The difference of the OS between the two groups was not significant $(\mathrm{p}=0.076)$ (Figure 3B).

\section{Adverse effects}

Table 3 presents all reported adverse events in each group. One patient with the history of coronary heart disease in T-CHOP group had chest pain after he received 1 cycle of T-CHOP. Coronary angiography showed a $90 \%$ stenosis of the left anterior descending artery. Coronary artery stent was implanted and he continued the chemotherapy of CHOP without thalidomide. More 
Table 1: Clinical characteristics of patients treated with T-CHOP or CHOP

\begin{tabular}{|c|c|c|c|}
\hline Clinical variable & $\begin{array}{c}\text { T- CHOP } \\
\mathbf{n}(\%)\end{array}$ & $\begin{array}{l}\text { CHOP } \\
\text { n (\%) }\end{array}$ & $P$ value \\
\hline Age & & & 0.357 \\
\hline$\leq 60 \mathrm{yr}$ & $22(68.8)$ & $26(78.8)$ & \\
\hline$>60 \mathrm{yr}$ & $10(31.2)$ & $7(21.2)$ & \\
\hline Stage & & & 0.390 \\
\hline I or II & $17(53.1)$ & $21(63.6)$ & \\
\hline III or IV & $15(46.9)$ & $12(36.4)$ & \\
\hline Serum lactate dehydrogenase & & & 0.897 \\
\hline$\leq 250 \mathrm{IU} / \mathrm{L}$ & $17(53.1)$ & $17(51.5)$ & \\
\hline$>250 \mathrm{IU} / \mathrm{L}$ & $15(46.9)$ & $16(48.5)$ & \\
\hline Performance status & & & 0.137 \\
\hline 0 or 1 & $28(87.5)$ & $24(72.7)$ & \\
\hline 2 & $4(12.5)$ & $9(27.3)$ & \\
\hline Extranodal involvement & & & 0.492 \\
\hline 0 or 1 & $32(100)$ & $31(93.9)$ & \\
\hline$\geq 2$ & 0 & $2(6.1)$ & \\
\hline International prognostic index & & & 0.343 \\
\hline 0 or 1 & $18(56.3)$ & $16(48.5)$ & \\
\hline 2 or 3 & $14(43.8)$ & $15(45.5)$ & \\
\hline 4 or 5 & 0 & $2(6.1)$ & \\
\hline Median cycles of chemo & 6 & 6 & 0.16 \\
\hline
\end{tabular}

Abbreviations: T-CHOP, Thalidomide plus cyclophosphamide, doxorubicin, vincristine, and prednisone.

Table 2: Response to treatment with T-CHOP or CHOP

\begin{tabular}{lccc}
\hline & $\begin{array}{c}\text { T-CHOP }(\mathbf{n}=\mathbf{3 2}) \\
\text { no. }(\boldsymbol{\%})\end{array}$ & $\begin{array}{c}\text { CHOP }(\mathbf{n}=33) \\
\text { no. }(\%)\end{array}$ & P value \\
\hline Complete response & $26(81.3)$ & $19(57.6)$ & 0.039 \\
Overall response rate & $31(96.9)$ & $26(78.8)$ & 0.030 \\
Partial response & $5(15.6)$ & $7(21.1)$ & 0.562 \\
Stable disease & $1(3.1)$ & $4(12.1)$ & $0.355^{*}$ \\
Progressive disease & 0 & $3(9.1)$ & $0.238^{*}$ \\
\hline
\end{tabular}

* Fisher's exact test

patients in the T-CHOP group than in the CHOP group experienced grade $1 / 2$ adverse events in sinus bradycardia (21.9\% vs $3.0 \%, \mathrm{p}=0.027)$, numbness $(59.4 \%$ vs $24.2 \%$, $\mathrm{p}=0.004)$, somnolence $(43.8 \%$ vs $0 \%, \mathrm{p}=0.000)$, and dizziness $(40.6 \%$ vs $15.2 \%, \mathrm{p}=0.022)$. It seemed that more patients in T-CHOP had rash $(18.8 \%$ vs $3.0 \%, \mathrm{p}=0.054)$. There was no difference in the overall incidence of grade 3 or 4 adverse events between T-CHOP group and $\mathrm{CHOP}$ group. None of the patient received prophylactic anticoagulants during the treatment. Deep Venous Embolism (DVT) was not seen in patients treated with T-CHOP and there was no treatment-related death.

One patient diagnosed as DLBCL in Dec 2006. He received T-CHOP for 6 cycles and got $\mathrm{CR}$ after the first two cycles. This patient relapsed in Apr 2012, he underwent autologous stem cell transplantation and got 2nd CR. In Feb 2016, he had enlargement of the lymphonode. He received biopsy and was diagnosed as 

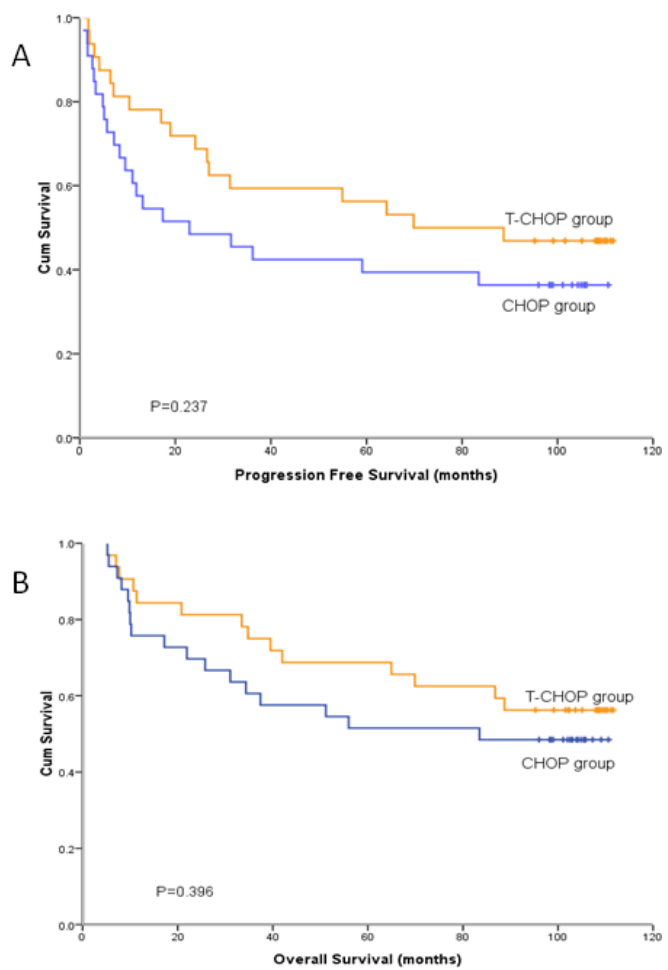

Figure 1: Progression free survival and overall survival curves of 65 patients with diffuse large B-cell lymphoma receiving T-CHOP and CHOP treatment. A. mPFS were 69.9 months in T-CHOP group and 22.9 months in CHOP group ( $\mathrm{p}=0.237$ ). B. mOS were not reach in T-CHOP group and 83.5 months in CHOP group ( $\mathrm{p}=0.396)$.
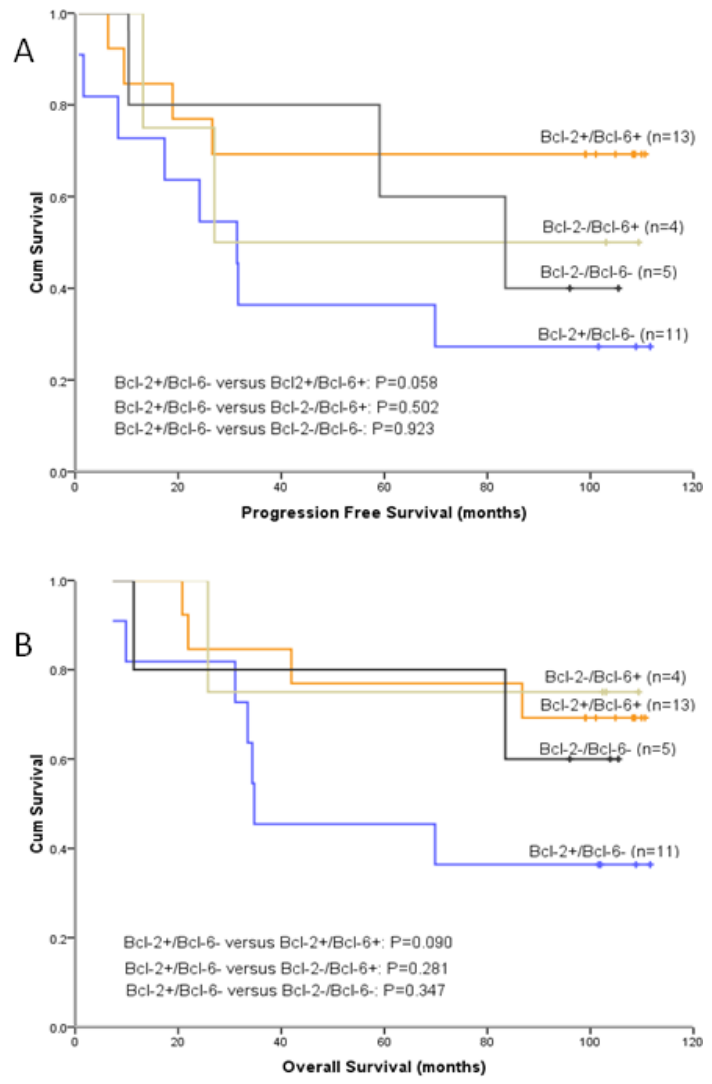

Figure 2: Patients with tumor tissue Bcl-2 positive and Bcl-6 negative (Bcl-2+/Bcl-6-) have the worst outcomes. A. PFS curves for 33 patients stratified by Bcl-2 and Bcl-6 immunoreactivity. B. OS curves for 33 patients in different Bcl-2 and Bcl-6 status. 
mantle cell lymphoma. It's hard to judge whether the MCL is transformed from DLBCL or the secondary malignancy.

\section{DISCUSSION}

In this randomized study, there were three main findings. First, we found that the CRR and ORR in T-CHOP group was significantly higher than that in CHOP group for previously untreated patients with DLBCL (Table 2), which met to the primary endpoint. Second, although the PFS and OS curves in two groups separated apparently since the beginning of the treatment, significantly increased CRR and ORR did not translate into prolonged PFS and OS in this study, which might be mainly attributable to the relatively small sample size of this study. In bcl-2+/bcl-6- subgroup, the median PFS in T-CHOP group was significantly longer than that in CHOP group (Figure 3A). But median OS in T-CHOP group was not significantly longer than that in $\mathrm{CHOP}$ group (Figure 3B). Finally, T-CHOP regimen was well tolerated, and produced a pattern of adverse events broadly similar to CHOP alone, with the exception of some mild thalidomide-related reactions such as sinus bradycardia, numbness, somnolence, dizziness and, perhaps, rash. In our study, no DVT was seen in T-CHOP group, which is different from the studies applying thalidomide to patients in west countries [23]. Perhaps the incidence of thalidomide-related thromboembolic events in Chinese patients is not as high as in western country patients [24].

Bcl-2 protein, an anti-apoptotic molecule, is expressed in $22-80 \%$ of DLBCLs and $\mathrm{Bcl}-2$ positivity has been reported to be associated with an unfavorable prognosis. Bcl-6 protein is expressed in about $47-84 \%$ of DLBCLs. Bcl-6 rearrangement and Bcl-6 protein expression were reported to be associated with favorable clinical outcome [25-28]. In the present study, Bcl-2 positivity and Bcl-6 negativity were found to be parameters predicting a significantly shorter PFS particularly (Figure 2 ). The Bcl-2 protein is correlated with the NF-kappa B pathway [29], and thalidomide can inhibit the activation of NF-kappa B [17], which might be the possible mechanism of thalidomide can overcome the unfavorable prognosis of Bcl-2. In our study, DLBCL patients with Bcl-2+/Bcl-6progressed rapidly and had short survival time when they
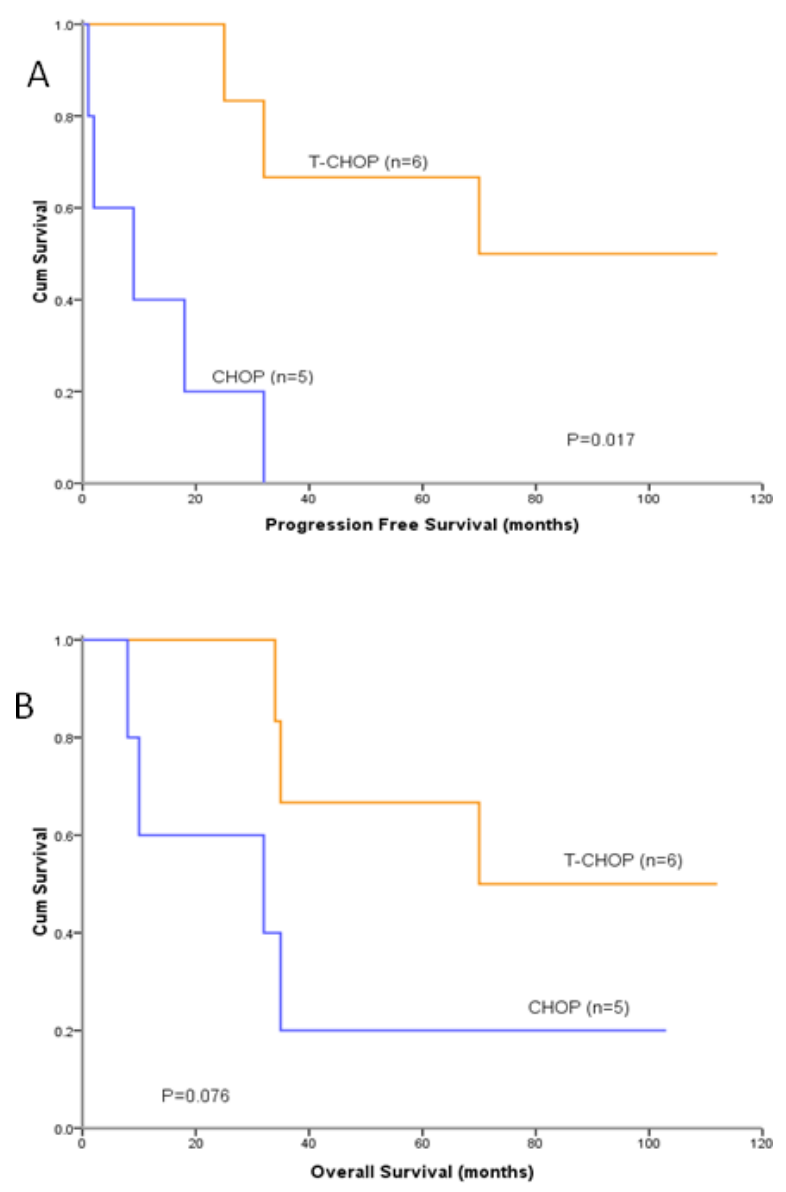

Figure 3: PFS and OS curves in Bcl-2+/Bcl-6- patients treated with T-CHOP or CHOP. A. PFS in T-CHOP group was significantly longer than that in $\mathrm{CHOP}$ group for $\mathrm{Bcl}-2+/ \mathrm{Bcl}-6$ - patients $(\mathrm{P}=0.017)$. B. Difference in OS between the two subgroups was not significant $(\mathrm{p}=0.076)$. 
Table 3: Common toxicities observed in patients in T-CHOP group and CHOP group

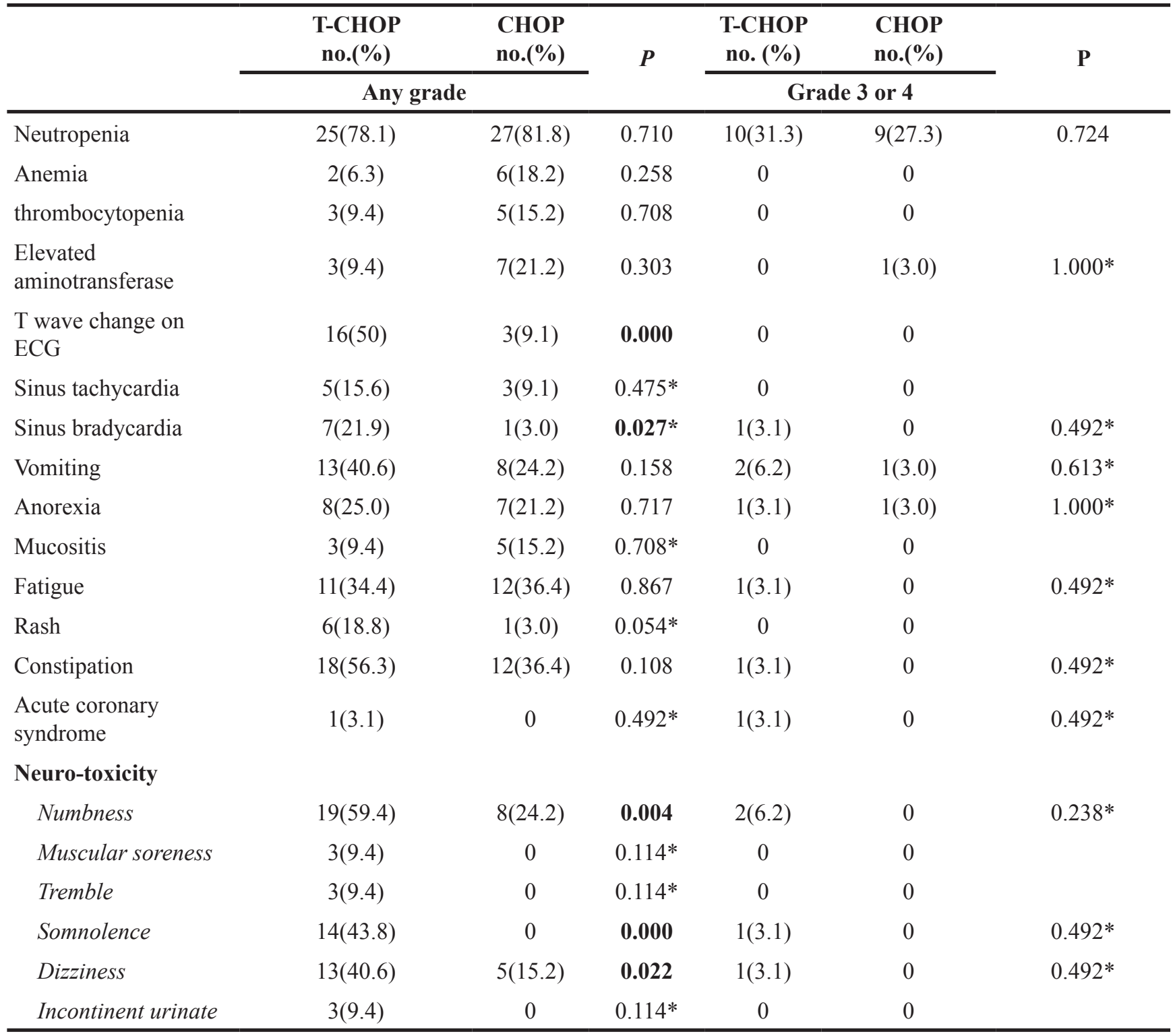

*Fisher's exact test

received CHOP regimen, but had relatively longer PFS and OS when received T-CHOP regimen (Figure 3).

Lenalidomide, an expensive analogue of thalidomide, showed significant activity in relapsed DLBCL. In a phase II study, lenalidomide combined with R-CHOP could overcome negative prognostic impact of non-germinal center B-cell phenotype in newly diagnosed DLBCL $[29,30]$.

Many cost-effectiveness analyses reported that adding rituximab to CHOP in DLBCL patients is costeffective [31-33]. In 2014, Khor S, et al reported the real world cost and cost-effectiveness of Rituximab for DLBCL patients in Canada. In this report, the addition of Rituximab is associated with improvement in survival but at a higher cost, thus may be not economically attractive in the elderly patients [34]. In china, for a patient with body surface area (BSA) of $1.6 \mathrm{~m}^{2}$, about 180,000 RMB Yuan is needed for 6 cycles of Rituximab, about 6,000 Yuan for 6 cycles of CHOP, and about 3,500 Yuan for 6 cycles of thalidomide. In some under-developed areas in middle and west China, many people with CD20 positive lymphomas cannot afford Rituximab. T-CHOP is a regimen that worth further investigation for this patient population.

Thus, this study has identified, for the first time, a safe and effective regimen for treating patients with DLBCL who cannot afford rituximab. In this study, no statistically significant difference in OS was found between the T-CHOP group and the CHOP group, which might be mainly attributable to the relatively small sample size of this study.

In conclusion, our study showed that T-CHOP was a highly effective and low-toxicity regimen that might be 
considered as a new regimen for the treatment of DLBCL patients who cannot afford rituximab. It is showed that the $\mathrm{Bcl}-2$ positive/Bcl-6 negative DLBCL patients gained survival benefit from adding thalidomide to the CHOP regimen.

As a phase II clinical trial designed in 2005, there were some limitations of our study. First, the sample size is relatively small to detect the difference in survival. Second, we didn't introduce the GCB/non-GCB subtype detection in this study, and $\mathrm{IHC}$ detection of Bcl-2 and Bcl-6 was not done in every patient. Third, the doseintensity of CHOP regimen in our study is lower than the standard regimen. Since there was no report about thalidomide combined with CHOP for newly diagnosed DLBCL patients published so far, our findings need to be further validated in the future.

\section{PATIENTS AND METHODS}

\section{Patients}

Patients age between 18 and 75 years old and had untreated diffuse large B cell lymphoma that had been diagnosed according to the World Health Organization classification. Additional enrollment criteria were as follows: an Eastern Cooperative Oncology Group performance status of 0-2; a more than 3 months life expectancy; and acceptable hematologic, hepatic, renal and cardiac function. Patients with a history of deep venous embolism (DVE) or pulmonary embolism (PE) were excluded. Pregnant and lactating women were also excluded.

\section{Ethical clearance}

This trial was approved by the institutional review board, the Fudan University Shanghai Cancer Center Ethics Committee for Clinical Investigation on Dec 29th, 2005. All patients were told that they should take $\mathrm{R}-\mathrm{CHOP}$ as the induction chemotherapy regimen if they can afford rituximab. Patients who cannot afford rituximab can choose to participate in this clinical trial. This trial is conducted in accordance with the Declaration of Helsinki and Good Clinical Practice. All patients provided written informed consent according to institutional guidelines.

\section{Randomization}

Eligible patients were randomly assigned according to the sequence of the time they signed the informed consent form. The randomization table was generated by the Stata software.

\section{Treatment and assessment}

Patients in the control group received $\mathrm{CHOP}$ regimen (cyclophosphamide $600 \mathrm{mg} / \mathrm{m}^{2} \mathrm{~d} 1$, epirubicin $60 \mathrm{mg} / \mathrm{m}^{2} \mathrm{~d} 1$, vincristine $1.4 \mathrm{mg} / \mathrm{m}^{2}$ [capped at $2.0 \mathrm{mg}$ ] d1, and prednisone
$60 \mathrm{mg} / \mathrm{m}^{2}$ per day on $\left.\mathrm{d} 1-5\right)$. Patients in the T-CHOP group also received thalidomide. Thalidomide $200 \mathrm{mg}$ per day was administered on days 6-21 in the first cycle, if the patient can tolerate it well the dosage will be added to 400 mg per day on days 6-21 since the second cycle or he/ she will continue to receive $200 \mathrm{mg}$ per day. Patients who had grade 4 neutropenia or febrile neutropenia after any cycle of chemotherapy were given G-CSF. The dose of cyclophosphamide and epirubicine will decrease $25 \%$ if the patient experience grade 4 hematological toxicity. CT imagings of lymphoma involved area were repeated every two cycles. No prophylactic anticoagulation medications were given to patients who received thalidomide. The treatment continued for a maximum of 8 cycles or until disease progression.

Tumor response and progression were determined according to the International Workshop Criteria [18]. The primary end point was $\mathrm{CR}$ rate, which include CR and $\mathrm{CRu}$. The secondary end points include: ORR, PFS and OS. Adverse events were graded according to the National Cancer Institute Common Toxicity Criteria for Adverse Events (version 3.0) and reported in detail.

\section{Statistical analysis}

Reported data showed that the CR rate in Chinese DLBCL patients treated with CHOP was 37.5-52.8\% $[20,21]$. In Gela $98-5$ study, the CR rate is $37 \%$ and the $\mathrm{CR}+\mathrm{CRu}$ rate is $63 \%$ for patients treated with CHOP [6]. We expected the $\mathrm{CR}$ rate of patients randomly assigned to receive $\mathrm{CHOP}$ or $\mathrm{T}-\mathrm{CHOP}$ to be $40 \%$ and $70 \%$, respectively. At least 31 patients are needed to be enrolled with 1:1 random assignment when significance was set at a one-sided 5\% type I error and at least $80 \%$ power. Response rates in each treatment group were compared using chi-squared tests. Progression-free survival and overall survival were analyzed with log-rank tests and expressed as Kaplan-Meier plots or Life Tables plots. Pearson chi-squared test or Fisher's exact test was used to analyze categorical variables. P-values were one-tailed for comparing the response rate and two-tailed for other tests, and statistical significance was set at $\mathrm{P}<0.05$. Statistical analysis was performed with SPSS software version 16.0 (SPSS, Chicago, IL)

\section{ACKNOWLEDGMENTS}

This work was supported by grants from Chinese Society of Clinical Oncology (CSCO), (No.200402).

We thank Ms. Lu Hongfen, pathologist in Fudan University, Shanghai Cancer Center, for her contribution in reviewing the pathological reports for all the patients included in this trial.

We thank Changzhou Siyao Parmaceuticals Co., Ltd for providing thalidomide for the patients who don't have medical insurance. 


\section{CONFLICTS OF INTEREST}

The authors declare no conflicts of interest.

\section{REFERENCES}

1. Wing CC, James O. Randy G, Joseph C, Pauline C, Peter J, Andrew N, Andrew T, Ennio P, Franco C, Francoise $\mathrm{B}$, Bertrand C, Faith H, et al. A clinical evaluation of the International Lymphoma Study group classification of NonHodgkin's lymphoma. Blood. 1997; 89:3909-18.

2. Fisher RI, Gaynor ER, Dahlberg S, Oken MM, Grogan TM, Mize EM, Glick JH, Coltman CA, Miller TP. Comparison of a standard regimen (CHOP) with three intensive chemotherapy regimens for advanced non-Hodgkin's lymphoma. N Engl J Med.1993; 328:1002-6.

3. Gaynor ER, Unger JM, Miller TP, Grogan TM, White LA, Mills GM, Balcerzak SP, Varterasian M, LeBlanc M, Fisher RI. Infusional CHOP chemotherapy (CVAD) with or without chemosensitizers offers no advantage over standard CHOP therapy in the treatment of lymphoma: a Southwest Oncology Group study. J Clin Oncol. 2001; 19:750-755.

4. Osby E, Hagberg H, Kvaløy S, Teerenhovi L, Anderson H, Cavallin-Stahl E, Holte H, Myhre J, Pertovaara H, Björkholm M. Nordic Lymphoma Group. CHOP is superior to CNOP in elderly patients with aggressive lymphoma while outcome is unaffected by filgrastim treatment: results of a Nordic Lymphoma Group randomized trial. Blood. 2003; 101:3840-3848.

5. Fisher RI, Miller TP, O'Connor OA. Diffuse aggressive lymphoma. Hematology. 2004; 2004:221-36.

6. Coiffier B, Lepage E, Briere J, Herbrecht R, Tilly H, Bouabdallah R, Morel P, Van D, Neste E, Salles G, Gaulard $\mathrm{P}$, Reyes F, Lederlin P, et al. CHOP chemotherapy plus rituximab compared with $\mathrm{CHOP}$ alone in elderly patients with diffuse large B cell lymphoma. N Engl J Med. 2002; 346:235-42.

7. Pfreundschuh M, Trümper L, Osterborg A, Pettengell R, Trneny M, Imrie K, Ma D, Gill D, Walewski J, Zinzani PL, Stahel R, Kvaloy S, Shpilberg O, et al. CHOP chemotherapy plus rituximab versus $\mathrm{CHOP}$ chemotherapy alone in young patients with good-prognosis diffuse largeB-cell lymphoma: a randomised controlled trial by the MabThera International Trial (MInT) Group. Lancet Oncol. 2006; 7:379-91.

8. Gratzinger D, Zhao S, Marinelli RJ, Kapp AV, Tibshirani RJ, Hammer AS, Hamilton-Dutoit S, Natkunam Y. Microvessel density and expression of vascular endothelial growth factor and its receptors in diffuse large B cell lymphoma subtypes. Am J Pathol. 2007; 170:1362-1369.

9. Shaffer AL, Rosenwald A, Staudt LM. Lymphoid malignancies: the dark side of B-cell differentiation. Nat Rev Immunol; 2002; 2: 920-32.
10. Alizadeh AA, Eisen MB, Davis RE, Ma C, Lossos IS, Rosenwald A, Boldrick JC, Sabet H, Tran T, Yu X, Powell JI, Yang L, Marti GE, et al. Distinct types of diffuse large-B cell lymphoma identified by gene expression profiling. Nature. 2000; 403:503-511.

11. Davis RE, Brown KD, Siebenlist U, Staudt LM. Constitutive nuclear factor kappaB activity is required for survival of Activated B Cell-like Diffuse Large B Cell lymphoma cells. J Exp Med. 2001; 194:1861-74.

12. D'Amato RJ, Loughnan MS, Flynn E, Folkman J. Thalidomide is an inhibitor of angiogenesis. Proc Natl Acad Sci USA. 1994; 91:4082-4085.

13. Haslett PA, Corral LG, Albert M, Kaplan G. Thalidomide costimulates primary human $\mathrm{T}$ lymphocytes, preferentially inducing proliferation, cytokine production, and cytotoxic respongse in the CD8+ subset. J Exp Med. 1998; 187:1885-92.

14. Davies FE, Raje N, Hideshima T, Lentzsch S, Young G, Tai YT, Lin B, Podar K, Gupta D, Chauhan D, Treon SP, Richardson PG, Schlossman RL, et al. Thalidomide and immunomodulatory derivatives augment natural killer cell cytotoxicity in multiple myeloma. Blood. 2001; 98:210-6.

15. Mitsiades N, Mitsiades CS, Poulaki V, Chauhan D, Richardson PG, Hideshima T, Munshi NC, Treon SP, Anderson KC. Apoptotic signaling induced by immunomodulatory thalidomide analogs in human multiple myeloma cells: therapeutic implications. Blood. 2002; 99:4525-4530.

16. Khan ZH, Simpson EJ, Cole AT, Holt M, MacDonald I, Pye D, Austin A, Freeman JG. Oesophageal cancer and cachexia: the effect of short-term treatment with thalidomide on weight loss and lean body mass. Aliment Pharmacol Ther. 2003; 17:677-682.

17. Keifer JA, Guttridge DC, Ashburner BP, Baldwin AS Jr. Inhibition of NF-kappa B activity by thalidomide through suppression of I kappa B kinase activity. J Biol Chom. 2001; 276:22382-22387.

18. Kaufmann H, Raderer M, Wöhrer S, Püspök A, Bankier A, Zielinski C, Chott A, Drach J. Antitumor activity of rituximab plus thalidomide in patients with relapsed/ refractory mantle cell lymphoma. Blood. 2004; 104:2269-71.

19. Cheson BD, Horning SJ, Coiffier B, Shipp MA, Fisher RI, Connors JM, Lister TA, Vose J, Grillo-López A, Hagenbeek A, Cabanillas F, Klippensten D, Hiddemann W, et al. Report of an international workshop to standardize response criteria for non-Hodgkin's lymphomas. J Clin Oncol. 1999; 17:1244.

20. Lin TY, Zhang HY, Huang Y, Guan ZZ, Shen T, Shi YK, Zhu J, Ke XY, Wang HQ, Shen ZX, Yu SY, Liu T, Shi XL. Comparison between $\mathrm{R}-\mathrm{CHOP}$ regimen and $\mathrm{CHOP}$ regimen in treating naive diffuse large B-cell lymphoma in China-a multi-center randomized trail. Ai Zheng. 2005; 24:1421-6. 
21. Wu HJ, Zhang QY, Chen DF, Guan XJ, Zhang BL, Ma J. Comparison of rituximab plus $\mathrm{CHOP}$ regimen and $\mathrm{CHOP}$ regimen alone for treatment of newly diagnosed patients with diffuse large B-cell lymphoma. Ai Zheng. 2005; 24:1498-502.

22. Shipp MA, Harrington DP, Anderson JR, Armitage JO, Bonadonna G, Brittinger G, Cabanillas F, Canellos GP, Coiffier B, Connors JM, Cowan RA, Crowther D, Dahlberg S. et al. A predictive model for aggressive Non-Hodgkin's lymphoma. N Engl J Med.1993; 329:987-994.

23. Urbauer E, Kaufmann H, Nösslinger T, Raderer M, Drach J. Thromboembolic events during treatment with thalidomide. Blood. 2002; 99:4247-8.

24. Zheng W, Wei G, Ye X, He J, Li L, Wu W, Shi J, Zhang J, Huang W, Xie W, Luo Y, Xue X, Lin M, et al. Bortezomib in combination with dexamethasone and subsequent thalidomide for newly-diagnosed multiple myeloma: a Chinese experience. Leuk Res. 2009; 33:1615-8.

25. Maeshima AM, Taniguchi H, Fukuhara S, Morikawa N, Munakata W, Maruyama D, Kim SW, Watanabe T, Kobayashi Y, Tobinai K, Tsuda H. Bcl-2, Bcl-6, and the International Prognostic Index are prognostic indicators in patients with diffuse large B-cell lymphoma treated with rituximab containing chemotherapy. Cancer Sci. 2012; 103: 1898-1904.

26. Gascoyne RD, Adomat SA, Krajewski S, Krajewska M, Horsman DE, Tolcher AW, O'Reilly SE, Hoskins P, Coldman AJ, Reed JC, Connors JM. Prognostic significance of $\mathrm{Bcl}-2$ protein expression and $\mathrm{Bcl}-2$ gene rearrangement in diffuse aggressive non-Hodgkin's lymphoma. Blood. 1997; 90:244-51.

27. Lossos IS, Jones CD, Warnke R, Natkunam Y, Kaizer H, Zehnder JL, Tibshirani R, Levy R. Expression of a single gene, BCL-6, strongly predicts survival in patients with diffuse large B-cell lymphoma. Blood. 2001; 98: 945-51.

28. Lossos IS, Czerwinski DK, Alizadeh AA, Wechser MA, Tibshirani R, Botstein D, Levy R. Prediction of survival in diffuse large-B-cell lymphoma based on the expression of six genes. N Engl J Med. 2004; 350:1828-37.
29. Zeng LP, Wen YL, Ma Y, Wang GQ, Li Y, Wang J, Xu LL, Zhang XM. Mechanism and clinical significance of anti-apoptotic gene bcl-2 expression in diffuse large B-cell lymphoma. Zhonghua Bing Li Xue Za Zhi. 2011; 40:377-81.

30. Hernandez-Ilizaliturri FJ, Deeb G, Zinzani PL, Pileri SA, Malik F, Macon WR, Goy A, Witzig TE, Czuczman MS. Higher response to lenalidomide in relapsed/refractory diffuse large B-cell lymphoma in nongerminal center B-cell-like than in germinal center B-cell-like phenotype. Cancer. 2011;117:5058-5066.

31. Nowakowski GS, LaPlant B, Macon WR, Reeder CB, Foran JM, Nelson GD, Thompson CA, Rivera CE, Inwards DJ, Micallef IN, Johnston PB, Porrata LF, Ansell SM, et al. Lenalidomide Combined With R-CHOP Overcomes Negative Prognostic Impact of Non-Germinal Center B-Cell Phenotype in Newly Diagnosed Diffuse Large B-Cell Lymphoma: A Phase II Study. J Clin Oncol. 2015; 33:251-257.

32. Johnston KM, Marra CA, Connors JM, Najafzadeh M, Sehn L, Peacock SJ. Cost-effectiveness of the addition of rituximab to $\mathrm{CHOP}$ chemotherapy in first-line treatment for diffuse large B-cell lymphoma in a population-based observational cohort in British Columbia, Canada. Value Health. 2010; 13:703-11.

33. Hornberger JC, Best JH. Cost utility in the United States of rituximab plus cyclophosphamide, doxorubicin, vincristine, and prednisone for the treatment of elderly patients with diffuse large B-cell lymphoma. Cancer. 2005;103:1644-51.

34. Groot MT, Lugtenburg PJ, Hornberger J, Huijgens PC, Uyl-de Groot CA. Cost-effectiveness of rituximab (MabThera) in diffuse large B-cell lymphoma in The Netherlands. Eur J Haematol. 2005; 74:194-202.

35. Khor S, Beca J, Krahn M, Hodgson D, Lee L, Crump M, Bremner KE, Luo J, Mamdani M, Bell CM, Sawka C, Gavura S, Sullivan T, et al. Real world costs and cost-effectiveness of Rituximab for diffuse large B-cell lymphoma patients: a population-based analysis. BMC Cancer. 2014; 14:586-596. 